\title{
CONSIDERAÇÕES SOBRE A VIOLÊNCIA FRIA
}

\author{
Ordep Serra* \\ Lorena Volpini* *
}

\begin{abstract}
Os autores discutem o conceito de vulnerabilidade e o aplicam ao horizonte da política, propondo tratar de vulnerabilidade política e relacioná-la com o que chamam de "violência fria”, ou seja, aquela cujos agentes conseguem blindagem institucional de modo a reduzir ou anular sua imputabilidade, por conta da dilação dos efeitos da ação predatória e da impessoalidade da sua relação com as vítimas, mas também por via de pressões sobre governos e agências de controle. A propósito, discutem a problemática da cidadania em quadro de grandes desigualdades e examinam fatores que tornam populações mais ou menos vulneráveis politicamente a danos socioambientais. Entre esses fatores, consideram a manipulação do planejamento urbano e regional com a limitação de seu caráter participativo e interferências de interesses privados na máquina pública, nesse policy-making. A propósito, examinam também a recorrente confusão proposital entre 'interesse de governo' e 'interesse público'.
\end{abstract}

Palavras Chave: Violência fria. Vulnerabilidade. Planejamento. Cidadania. Desigualdade.

Para explicar o que entendemos por "violência fria", tema central deste artigo, temos de esclarecer o que chamamos de vulnerabilidade política, pois as duas coisas estão intimamente ligadas. O primeiro passo indispensável é precisar em que sentido empregamos o termo substantivo da expressão grifada. Se quisermos defini-lo de forma a torná-lo operacional em termos analíticos, temos de limitarlhe o alcance. Tomada lato sensu, a condição de vulnerabilidade tem abrangência tal, que torna impossível aplicá-la de modo distintivo a situações humanas particulares. O motivo é claro: em princípio, todos somos vulneráveis. Invulnerável não há ninguém. Como dizia Guimarães Rosa, "viver é muito perigoso". A nós, humanos, bem cedo nos desperta o sentimento da derrelição. ${ }^{1}$

\footnotetext{
* Universidade Federal da Bahia - UFBA. Faculdade de Filosofia e Ciências Humanas. Departamento de Antropologia e Etnologia.

Estrada de São Lázaro, 197. Cep: 40210-740. Salvador Bahia - Brasil. ordepserra@gmail.com

** Universidade Federal da Bahia - UFBA. Programa de Pós-Graduação em Antropologia.

Estrada de São Lázaro, 197. Cep: 40210-740. Salvador -

Bahia - Brasil. lorenavolpini@gmail.com

${ }^{1}$ Esse sentimento nos marca a consciência, que nasce ferida pela intuição da própria finitude. Segundo Unamuno [1983 (1913)], ela desperta no espanto com a descoberta da
}

Temos, pois, de começar restringindo. Só vamos falar de "vulnerabilidade" em termos relativos. Usaremos esse nome para designar a exposição a riscos em princípio evitáveis, ou, pelo menos, controláveis, mas que, de fato, escapam, ou podem escapar, ao controle dos sujeitos, incidindo em circunstâncias a que eles não podem se furtar facilmente e em meio dos quais não têm como desligar-se sem grandes perdas. Dano reconhecido inevitável não constitui propriamente risco. A inevitabilidade da morte como destino último de qualquer vivente é um dado absoluto, não relativo: não torna, per se, um mortal mais vulnerável que outro. Mas consideramos vulneráveis aqueles cuja morte pode ocorrer em determinadas circunstâncias nas quais outros se defendem bem da possibilidade do perecimento. O mesmo se

morte, fim certíssimo. O golpe que punge e acorda a consciência lhe manifesta sua irônica fragilidade, em contradição com seu privilégio - o reconhecimento de si, o ser para si -, face à "opacidade" cognitiva do mundo físico - vago e cego, mas capaz de aniquilar o "roseau pensant" que lhe acolhe a aparição. Pascal (Pensées, fr. 347) o exprimiu muito bem. Esse páthos da consciência se acentua de um modo especial nas vicissitudes que nos fazem exclamar: derelicti sumus in mundo. A Geworfenheit significa também exposição a riscos que não foram assumidos, marcas necessárias da existência que se apercebe como destino, ou seja, como não escolhida nem "solicitada". 
aplica a morbos e acidentes. Em suma, quando se diz que um grupo é vulnerável, está implícita sua comparação com outros que eludem (podem eludir) com sucesso certos danos aos quais o indigitado se mostra muito suscetível. De resto, quem fala em vulnerabilidade tem de dizer a que. De novo, isso decorre de que, em termos gerais, todos somos vulneráveis a danos diversos, tanto conhecidos (ou reconhecíveis) como ignorados, capazes de surpreendernos quando se apresentam.

Cabem ainda outras restrições para que o conceito funcione em quadro histórico e seja sociologicamente útil: deve referir-se a riscos que, por um lado, não são assumidos de propósito e que, por outro, transcendem a margem de tolerância admitida no código cultural do grupo ameaçado. Correr riscos, aceitos de forma esclarecida, pode ser inerente a práticas e ofícios aceitos, reconhecidos. A margem de tolerância que lhes corresponde varia transculturamente.

Sendo um processo, a vulnerabilidade tem uma dinâmica: pode aumentar ou diminuir por conta de fatores variáveis. Entre esses fatores, destacam-se o grau de percepção dos riscos e de sua etiologia por parte de quem é afetado, o volume de recursos disponíveis para fazer-lhes face, o quantum e o tempo de exposição etc. Quando sobre a qualidade de vida dos sujeitos pesam ameaças relacionadas com governança e distribuição do poder na sociedade, cabe falar em vulnerabilidade política. considera seu território, com a preservação de seus interesses e valores, assim como a manu- tenção de sua capacidade de reprodução social e biológica. É certo que essas condições de segurança podem ser limitadas (ou mesmo tornadas nulas) por catástrofes naturais. Todavia fatores antrópicos podem produzir o mesmo efeito. Se as ditas "condições de segurança" se mostram passíveis de restrição ou supressão por conta de decisões exógenas, tomadas longe do grupo interessado, sem o considerar, e sem que ele participe do processo, falamos de vulnerabilidade política.

"Preservação de interesses e valores" vem a ser uma condição indispensável para que alguma segurança se verifique, pois, como se sabe, uma população pode ser submetida a constrangimentos sérios e injunções muito limitadoras em sua própria terra, pode "perder espaço" no seu próprio espaço. Basta que se pense na condição dos hilotas, de povos dominados por um inimigo opressor e (ou) submetidos a violenta colonização. As populações que veem "eleitas" pelos critérios do racismo ambiental para a exposição a condições insalubres, a resíduos tóxicos etc. se veem na mesma situação.

A avaliação da vulnerabilidade política exige que se dimensione a capacidade de a população em estudo deliberar sobre o próprio destino. Sem isso, torna-se impossível falar em um bom nível de "desenvolvimento humano." Impossível dizer que existe razoável qualidade de vida quando se experimenta incerteza quanto ao futuro; quando o grupo em apreço pode ser compelido a deslocar-se, ou a submeter-se a mudanças socioambientais violentas que ultrapassem os recursos disponíveis para enfrentá-las; ou quando ele sequer tem acesso a informações claras e precisas sobre grandes mudanças propostas - no interesse de outros para o espaço onde vive.

No Brasil, populações têm sido erradicadas, retiradas de seus nichos históricos, cerceadas em seus direitos fundamentais e, por fim, ameaçadas em sua sobrevivência física, como resultado de deslocamento compulsório (direta ou indiretamente imposto) a que, não raro, se somam agressões de todo gênero em caso de 
resistência maior. Não poucas se veem submetidas a pressões severas para que abandonem o lugar onde vivem ou partes dele, resistindo enquanto podem. É o que hoje experimenta, por exemplo, a comunidade quilombola de Rio dos Macacos, no município de Simões Filho, Região Metropolitana de Salvador.

Acontece também que grupos significativos de moradores de uma área tenham de deixá-la em consequência da gentrificação, perdendo qualidade de vida. Também, nesse caso, cabe falar de vulnerabilidade política e, em muitos casos, de violência fria.

Essas situações se verificam em nosso país de modo tristemente repetitivo. Elas têm a ver com o que chamaremos de distribuição desigual da cidadania, com a ausência de freios eficazes para a ganância dos grandes capitais e com a perversão ou o desarranjo do planejamento, em concomitância com vícios na produção de políticas públicas. As comunidades tradicionais e os pobres, em geral, são as maiores vítimas desses processos.

Quanto a "distribuição desigual da cidadania” em nosso país, basta, para caracterizá-la, o que disse o Ministro Joaquim Barbosa, ao tomar posse do cargo de Presidente do Supremo Tribunal Federal: ele acusou a existência de "um grande déficit de Justiça entre nós". De fato, é inegável que, no Brasil, "[...] nem todos os cidadãos são tratados com a mesma consideração quando buscam a Justiça. O que se vê aqui e acolá é o tratamento privilegiado." Mas o que ele disse da Justiça pode estender-se a outras áreas de governo Bem o registrou o doutor Fausto de Sanctis, Desembargador do Tribunal Federal da Terceira Região, em entrevista concedida a Le Monde Diplomatique em setembro de 2011: "O Legislativo, quando faz as leis, as faz de forma a privilegiar situações de irresoluções jurídicas, ou seja, estabelece códigos, leis e regulamentos complexos em demasia para que, de alguma forma, lá na frente, sejam vendidas facilidades". O mesmo procedimento é adotado pelo Executivo, como ponderava o citado desembargador: "No Brasil, parece que, com a justificativa da governabilidade, esses dois poderes [Executivo e Legislativo] se fundiram. E nós temos um Judiciário que, com suas decisões, reafirma esse estado de coisas, prestigia a desigualdade” (Brasilino, 2011).

Como bem se vê, ao pensar a cidadania, é preciso abordar as desigualdades factuais entre grupos pertinentes a um mesmo estado-nação mas diferenciados por raça, etnicidade, religião, gênero, orientação sexual etc. Dá-se que determinados segmentos encaram exclusões diversas da participação plena na vida pública, apesar da igualdade formal que a condição de cidadãos lhes atribui, na letra da lei. Por si só, a pobreza exclui da cidadania amplos setores da população.

A contratualização da cidadania anda junto com a expansão do capitalismo, difusor de uma visão de mundo e de um movimento político global tendentes a dissolver as fronteiras entre mercado e sociedade civil, esfera pública e comunidade política (Somers, 2008). Essa tendência (global) vai de encontro à privatização, à evitação de toda forma de regulamentação e, principalmente, à mercantilização de serviços públicos como saúde, educação, controle de poluição, segurança, todavia considerados por muitos "requisitos não contratuais do bem comum” (Somers, 2008, p. 72).

Desdobramentos desses processos são os casos de grilagem de terras e as políticas de habitação submetidas aos interesses do capital imobiliário, práticas que frequentemente resultam em atos de desapropriação e deslocamento violento de populações urbanas e rurais em função de projetos desenvolvimentistas ou de megaeventos globais. Nesse processo, direitos básicos, como segurança, integridade física e salubridade, entre outros, tornam-se progressivamente bens de mercado, à venda para poucos.

Claro está que isso não acontece apenas no Brasil. Mas, seja onde for, uma coisa é certa: pode acarretar consequências muito graves a situação em que, por um lado, um segmento privilegiado mostra uma extraordinária capacidade de interferência na gestão da coisa pú- 
blica e, por outro, o controle social das práticas governamentais se verifica falho. Estudos sobre a crise que abalou a maior economia do mundo têm mostrado que ela foi precedida por um longo e sistemático trabalho de desregulamentação do mercado financeiro, a fim de permitir que alguns grupos e instituições privadas maximizassem seus lucros de modo praticamente infrene. ${ }^{2} \mathrm{O}$ descontrole resultante foi terrível para muitos: basta lembrar o pique do desemprego e os efeitos sinistros da explosão da bolha imobiliária. Grande número de cidadãos descobriu-se vulnerável a carências que antes sequer imaginava - e essa insegurança ainda perdura, atingindo vastas camadas da população norte-americana. Muitas pessoas que perderam suas casas no jogo sujo de financiamentos inescrupulosos nem de longe supunham que isso pudesse acontecer. Descobriram-se vulneráveis ex post facto. Foram vítimas do que chamaremos de "violência fria", como se pode designar aquela cujos agentes conseguem revestir-se de sutil impessoalidade e, assim, blindar-se eficazmente contra a reação dos atingidos, que não confrontam de forma direta. Uma descrição admirável disso se encontra nas páginas de Vinhas da Ira, de John Steinbeck - logo no início, quando ele mostra, de forma dramática, o sentimento de ๑ impotência de pequenos produtores rurais a N quem foram tomadas suas terras, e se acharam 宽 obrigados a abandoná-las, não vendo contra quem reagir, nem sabiam como.

Insistimos que é necessário levar em conta a violência fria quando se fala de vulnerabilidade, segurança, desenvolvimento. Em geral - embora nem sempre -, ela decorre da abusiva ingerência de grupos privados na gestão da coisa pública, com a fragilização dos controles sociais e das próprias normas (via desregulamentação), além do emperramento proposital das agências de fiscalização e regulação. Quando se dá dessa forma - a mais comum -, ela opera necessariamente com limitação de acesso público a informações sobre ${ }^{2}$ Ver a respeito: Cassidy, 2010. Cf. também Krugman, 2011. planos e projetos, sobre todo o policy-making. Sempre acarreta consequências que implicam prejuízos graves para significativas parcelas da população, mas seus protagonistas se empenham na sua camuflagem, na fuga à evidência dos danos que causam e dos direitos que desconsideram. Faz parte de sua estratégia evitar conflito aberto, tanto quanto possível. É que o conflito manifesto e chocante pode criar a evidência cuja ocultação desejam.

No Brasil, porém, mesmo "a violência fria” pode aquecer-se de forma abrupta, combinar-se à coerção direta, aberta e rude, exercida de forma privada (via milícia clandestina, empresas de segurança etc.), ou mesmo com o emprego do próprio aparelho de estado para tal fim: não se descarta sequer o uso de força pública para a violação de direitos constitucionais de milhares de cidadãos, conforme sucedeu, por exemplo, no famoso caso da desocupação do bairro de Pinheirinho, da cidade paulista de São José dos Campos, em 2011. ${ }^{3}$ Dá-se que, neste país, temos violência em todos os graus de temperatura.

A violência fria pode ser exercida por instituição ou grupo privado, sem envolvimento do poder público, burlando instâncias de governo, como no caso de indústrias farmacêuticas, que põem à venda remédios inócuos e, desse modo, causam danos severos à saúde de muitos cidadãos, provocando lesões e mortes por via do agravamento profundo de estados mórbidos. A rigor, esse procedimento pode caracterizar-se como homicida. Mas, legalmente, não é fácil fazer com que os autores

${ }^{3}$ Em 22 de janeiro de 2012, a Polícia Militar do Estado de São Paulo, com o concurso de agentes civis, desalojou 1600 famílias do bairro de Pinheirinho, São José dos Campos, usando balas de borracha, agressões e truculência. 205 casas foram demolidas sem que os bens dos moradores fossem retirados. O procurador do Estado de São Paulo, Dr. Márcio Sotelo Felipe, enumerou várias irregularidades no processo de despejo, destacando o fato de que a reintegração de posse foi concedida sem ter sido solicitada pelo proprietário do terreno ocupado pelas famílias, a massa falida da Empresa Selecta, do megaespeculador Naji Nahas. A ordem de desocupação contrariou liminar da Justiça Federal que desautorizava o despejo das famílias. A derrubada das casas foi realizada de surpresa, de madrugada, sem o acompanhamento de oficiais de justiça e assistentes sociais. Um grupo de ilustres advogados e juristas formalisociais. Um grupo de ilustres advogados e juristas form
zou denún do abuso à corte internacional da OEA. 
de tais homicídios respondam por eles e sejam efetivamente categorizados como assassinos. Cabe ao Estado impedir que esse tipo de crime aconteça e puni-lo quando ocorre, mas nem sempre isso se verifica de modo satisfatório. Do ponto de vista ético, a omissão do Estado o torna cúmplice do crime. Todavia essa cumplicidade raras vezes é punida ou mesmo advertida, ou categorizada como ilícito.

A violência fria pode efetivar-se por via de práticas de agentes políticos que usam a máquina de governo com objetivos particulares e, assim fazendo, colocam em risco a população, prejudicam-na de forma grave, por ação ou omissão calculada. Com isso, eles provocam, por vezes, terríveis danos. Um caso recente foi exposto pelo jornalista Jânio de Freitas, a propósito de agravantes das cheias que fizeram tremendos estragos no Rio de Janeiro:

Em Duque de Caxias, e sobretudo em Xerém, na vizinhança do Rio, a enchente trouxe um perigo agravado [...]. Já por um mês antes da chuvarada não havia coleta de lixo naquela região de alta densidade populacional. Represália à derrota nas eleições, explica o noticiário. [...] Abandonar a coleta de lixo foi um ataque pensado e calculado à saúde pública. [...]. Semanas antes da enchente, já o noticiário exibia monturos de lixo pelas ruas, a população em desespero incendiando vários deles. A chuva os desmanchou e criou uma lama de lixo e contaminações muito maior e mais espalhada do que as enchentes em geral provocam. [...] Mas nada se ouve sobre ações penais (Freitas, 2013, p. B7).

Não se trata de uma exceção, como o jornalista bem sublinhou:

Em várias cidades do interior de São Paulo, de Minas, do Nordeste e do Estado do Rio, prefeitos derrotados vingaram-se de suas populações criando ou agravando o caos. As escassas notícias a respeito informam de destruição de remédios do estoque municipal, desmontagem das condições mínimas de funcionamento de serviços (Freitas, 2013, p. B7).

Os prefeitos que causam essas calamidades geralmente não são responsabilizados. É mesmo raro que isto aconteça. E, quando sucede serem eles processados, contam com as falhas do judiciário e suas delongas, com o amparo da chicana. Valem-se, também, do tráfico de influências e de outros meios escusos para escapar da punição. Muitas vezes, têm êxito. Assim os desastres que eles suscitam ficam por conta da natureza, do acaso, da Moira. Desgraças provocadas de modo calculista viram fatalidade. Os responsáveis são conhecidos, são notórios, mas sua culpa se dilui no esquecimento, na leniência geral. A população sente-se impotente, chora sua desgraça como se fosse imposição do destino.

Vejamos outros tipos de situação que tipificam atos de violência fria. O que ocorre, por exemplo, quando se quer realizar uma grande obra urbanística, como uma rodovia ou uma ponte? Uma vez aprovado o projeto, procedese à desapropriação, por utilidade pública, das áreas de interesse para a obra. A desapropriação é um ato da administração pública, portanto um ato do Estado, justificado por interesse público. Um dos princípios mais importantes do Estado democrático de direito corresponde ao imperativo da prevalência do interesse público sobre o privado. Todavia, importa não confundir interesse público com interesse de Estado. Interesse público significa interesse da coletividade e não da administração, ou do administrador. É o interesse da coletividade que tem supremacia sobre o interesse do particular. Definir o interesse público a partir da identidade de quem tem o ônus de cuidá-lo (o Estado) constitui uma inversão lógica. Como o Estado democrático é instrumento de realização dos interesses da coletividade, o interesse público existe antes do Estado, e não em razão dele. Segue-se que o interesse público, entendido como interesse da coletividade, é o fim último da atuação estatal.

Existem inúmeras dificuldades para uma definição unívoca de interesse público numa sociedade plural. Além disso, há interesses públicos concretos que podem entrar em conflito. No caso da função de planejamento territorial, por exemplo, a autoridade administrativa competente deve decidir que interesses defender, entre os interesses públicos envolvidos e confli- 
tantes: o interesse econômico-produtivo, o interesse habitacional, ou o interesse paisagístico.

Num Estado democrático, não há dúvida de que o caráter plural e diversificado da coletividade deve ser considerado na ponderação dos interesses.

Dificuldades para uma ponderação efetiva de interesses diversos - e, por vezes conflitantes - ligam-se ao fato de que a diversidade do corpo social não se acha representada de forma efetiva nas instituições responsáveis pela tomada de decisões. Para que os diversos interesses entrem na ponderação, seus portadores devem todos participar do processo decisório, mediante uma discussão verdadeiramente pública, institucionalizada através de instrumentos hábeis, sem desconsiderar suas diferenças. Isso constitui um desafio para a democracia representativa e, de forma mais ampla, para a nossa herança política moderna. Os riscos que correm diversos grupos portadores de interesses distintos, por não terem voz, podem decorrer de não estarem eles representados de forma efetiva nas instituições, mas também costumam derivar da limitação dos mecanismos participativos concebidos a partir de uma ideia universalista de generalidade e “same-ness" (Young, 1998). O primeiro passo é reconhecer as diferenças e não rechaçá-las ๑ através do habitual artifício de considerá-las ڤે circunscritas a uma esfera do privado supostamente incapaz de atingir a esfera pública.

\& partam do pressuposto de uma humanidade 今 indiferenciada. ${ }^{4}$ Não somente esse tipo de ge-

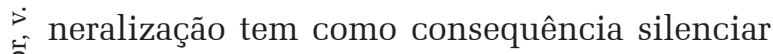

$\stackrel{\pi}{2}$ Herança do pensamento político moderno, o ideal do డ్ reinado público da cidadania como a expressão de uma - vontade geral e homogênea é considerado problemático por alguns autores (Kymlicka, 1998, Young, 1998), pois

J opera como uma demanda de homogeneidade entre cida-

dãos (Young, 1998). Para um aprofundamento dessa crítica

às abordagens universalistas da cidadania, que sustenta a passagem de um universalismo político a um universalismo epistemológico, remetemos à leitura de Young, 2008. portadores de interesses diferenciados. Recorrentes em nossa história política são discursos baseados nos mitos do progresso, do desenvolvimento que, além de justificarem e promoverem políticas governamentais discutíveis, produzem uma falácia muito poderosa (Holston, 2008). Essa falácia consiste em generalizar como interesse público, ou bem comum, algo que, em verdade, nada mais é que o interesse de uma parcela - e produzir, de modo artificioso, uma adesão da população a esse tipo de discurso. Desdobramentos concretos de semelhante engodo são os atos de repressão que tolhem reivindicações legítimas, tratadas como questão de segurança e de ordem pública, em vez de reconhecidas como questões políticas e socioeconômicas controversas, a serem discutidas.

Os processos de generalização descritos podem silenciar os portadores de interesses diferenciados, resultando em maior vulnerabilidade dos grupos submetidos a consequências injustas de intervenções voltadas para os objetivos de uma minoria privilegiada. Esses grupos veemse, frequentemente, impossibilitados de identificar os reais portadores de interesses opostos aos seus. Quando isso ocorre, não conseguem formular discursos críticos de oposição legítima, nem empreender ações coletivas tempestivas em defesa dos próprios direitos fundamentais.

Muitas vezes, calamidades resultam de intervenções em áreas onde o Estado assume as metas de lucro de poucos como se foram de interesse público. Não raro, essas calamidades são descritas como se não houvesse autores. Os responsáveis ficam ocultos atrás de uma neutra máscara institucional e, mesmo quando não conseguem esconder de todo sua responsabilidade, logram manter-se, na prática, inimputáveis, ou quase. Muitas vezes, ficam mesmo impunes. Os danos que eles causam "naturalizam-se", ou são postos na conta de uma transformação histórica, de uma injunção do progresso, "das circunstâncias", e por aí vai... As vítimas se amontoam na vala comum do anonimato. A distância temporal entre os atos danosos e sua consequência também pode 
servir de biombo para os agressores. Eles podem alcançar até um sucesso mais completo: a legalização de suas práticas de "violência fria".

Daremos logo um exemplo dessa situação-limite, em que se legaliza o ilegítimo com pesadas consequências: os próceres do agronegócio, no Brasil, têm conseguido manter em uso legal agrotóxicos da mais alta periculosidade, proibidos praticamente em todo o mundo. Doenças graves e mortes penosas ocorrem em consequência disso, mas, entre a causa e o resultado, medeia um tempo que não deixa a etiologia manifestar-se com clareza chocante. Mesmo havendo comprovação do nexo etiológico, os casos não são devidamente registrados nem computados, de modo que os óbitos se trivializam, escapando, até, aos levantamentos epidemiológicos. Assim, danos severos à saúde pública não são devidamente apreciados, e o desgaste ambiental que pode comprometer gerações permanece escondido. No entanto, os responsáveis sabem muito bem desses efeitos, não ignoram o impacto deletério de sua prática. O dano severo causado conscientemente, que afeta a vida de muitos, por certo deve caracterizar-se como violência. A ilusória distância entre a determinação e o resultado, o fato de que os ofensores não interagem diretamente com as vítimas e não as visualizam nem tomam conhecimento delas no plano pessoal, mantendo-se distantes, são os fatores que tornam "fria" tal violência. Ela só pode se realizar nos casos que aqui nos interessam, com apoio de cúmplices poderosos, investidos de autoridade (governantes, conselheiros, funcionários etc.). A vulnerabilidade da população nas áreas em que sucede agressão impune ao coletivo pode aumentar por conta disso. Assim, a impunidade de que desfrutam agentes responsáveis por danos de grande escala serve de estímulo a outros empreendimentos do mesmo tipo. As carências de que a população atingida sofre também a fragilizam nesse sentido. ${ }^{5}$

${ }^{5}$ Pela mesma lógica perversa, a desigualdade regional e o racismo ambiental orientam, também, a escolha de espaços para formas de exploração predatória de recursos naturais, ou até para a deposição de dejetos perigosos etc.
Além da corrupção pura e simples de agentes públicos, ou de sua intimidação - ou ainda, em última instância, de sua criminalização, no caso de se fazerem denunciantes - concorrem para viabilizar a agressão ao coletivo as manobras políticas que envolvem o desaparelhamento de agências estatais reguladoras, o enfraquecimento de conselhos comunitários, a criminalização de lideranças de movimentos sociais etc. Mas convém assinalar um fator condicionante que muito se elide: a manipulação do aparelho de Estado com fins de priorizar interesses privados em detrimento do público vem a ser muito favorecida quando se verifica um eclipse do planejamento propriamente dito, sua perversão ou distorção.

A distorção principal consiste na orientação perversa do planejamento, que deveria ser público, mas resulta conduzido por empreendedores privados e divorciado dos interesses da população local, ao cabo privada de meios de intervir no processo de tomada de decisões que lhe afetam significativamente a vida.

Outro fator que pesa na aferição da vulnerabilidade política de uma população vem a ser o próprio histórico de suas experiências em termos de danos socioambientais e outros, considerando:

- o passivo socioambiental e o balanço de eventuais reparações;

- o passivo etnopolítico e o balanço de eventuais reparações:

- a ponderação da recorrência de conflitos com base na demanda de direitos a propriedade, posse e usufruto de território e de recursos naturais por parte de nativos na área considerada;

- a acessibilidade das instâncias públicas a demandas comunitárias e o padrão de resposta correlato;

- a ponderação dessas demandas e dos direitos comunitários no planejamento regional com base na participação dos interessados;

- a eficácia dos controles sociais relativos à execução de políticas públicas e de intervenções diversas na área, o que tem a ver, entre 
outras coisas, com o grau de organização da sociedade civil nesse âmbito, mas também com os procedimentos de governança;

- o grau de aparelhamento e de eficácia dos controles governamentais legalmente fundados, no que toca a iniciativas particulares capazes de afetar o interesse público na área em estudo (atuação de agências reguladoras etc.)

- a natureza do planejamento efetuado na esfera pública de governo, a efetividade da participação comunitária no processo e seu controle social.

Quanto ao último requisito listado acima cabe um esclarecimento. A insuficiência do planejamento urbano e regional nem sempre significa inexistência de planos, falta de projetos. Mesmo que eles proliferem, deve-se falar em crise ou eclipse do planejamento se projetos e planos não formam corpo num conjunto sistemático, ordenado, estruturado de modo a compor uma visão sinótica e de longo alcance das áreas visadas e de seu potencial de desenvolvimento, expressa em diretrizes gerais, com metas definidas e horizonte temporal significativo, tendo por base estudos suficientes e consultas que garantam efetiva participação de todos os segmentos organizados da população interessada. A multiplicação de projetos pontuais, sem - articulação que os coordene, nem de longe su๙ pre a necessidade assinalada. \& o Governo da Bahia perdeu quadros técnicos e os tornou-se muito dependente da iniciativa pri$\vec{v}$ vada no tocante a planejamento e elaboração de projetos públicos.

Em encontro realizado em 18 de fevereiro de 2010, representantes do Movimento Vozes de Salvador e do Fórum "A Cidade Também é Nossa”, que reúnem dezenas de instituições da sociedade civil organizada com sede em
Salvador, apontaram ao Governador do Estado essa carência, assinalando a necessidade ineludível de uma instituição voltada para a qualificação de quadros, a realização de pesquisas e de avaliações de políticas públicas: um centro de formação, subordinado à Secretaria Estadual de Planejamento, capaz de fazer-se responsável pela geração de um pensamento estratégico sobre o desenvolvimento baiano. Na oportunidade, sugeriu-se também que fosse reaparelhada a Companhia de Desenvolvimento do Estado da Bahia (CONDER), de modo que ela voltasse a ter sua especificidade e seu foco original. Essa proposta refletiu a preocupação de todos com a situação atual da Região Metropolitana de Salvador, ${ }^{6}$ pois a CONDER, instituída em 1973 com a incumbência de planejá-la, nunca conseguiu criar um plano diretor para a cidade. Mais grave ainda: quando incorporou a Habitação e Urbanização do Estado da Bahia S/A (URBIS), além de perder o foco metropolitano, a CONDER simplesmente deixou de ser um órgão de planejamento, passando a executar obras em todo o estado. "Fazejamento" dispersivo, em vez de planejamento.

Como se sabe, a capital baiana vive uma profunda crise (econômica, fiscal, social) e tem como única opção de crescimento a expansão para fora, rumo à RMS. Como argumentaram as lideranças presentes ao referido encontro, a fim de garantir a Salvador crescimento ordenado nesse contexto, torna-se indispensável a criação não só de um órgão de planejamento técnico e autônomo como também de um Conselho Metropolitano com representação do estado, dos municípios envolvidos e da sociedade civil. ${ }^{8}$

${ }^{6}$ A RMS compreende os municípios de Camaçari, Candeias, Dias d'Âvila, Itaparica, Lauro de Freitas, Madre de Deus, Mata de São João, Pojuca, Salvador, São Francisco do Conde, São Sebastião do Passé, Simões Filho e Vera Cruz. Sua área de influência abrange os estados da Bahia e de Sergipe, parte de Alagoas, Pernambuco e Piauí. É a RM mais rica do Nordeste.

${ }^{7}$ URBIS - Habitação e Urbanização do Estado da Bahia S/A.

${ }^{8}$ Buscando superar a inconsistência do PDDU de Salvador, que, entre outros defeitos, não levou em conta a RMS, o Fórum e o Movimento propuseram também a realização, em parceria com o Governo do Estado, do Seminário Salvador Metrópole, de que foi apresentado projeto à Secretaria do Desenvolvimento Urbano do Estado da Bahia. Como então se ponderou, o debate sobre o tema interessa 
Ainda no referido texto, evocou-se o histórico de grandes projetos frustrados (paralisados a meio caminho ou com sérios problemas), cujo peso morto onera a Bahia e principalmente sua capital: projetos como o Parque Atlântico, a Via Náutica, o Bonde Moderno, o Metrô etc., que não funcionaram por falta de planejamento adequado e por terem sido implantados sem consulta à sociedade, em particular sem que se ouvisse a comunidade técnica representada pelas associações profissionais, pelos grupos ambientalistas e pelos núcleos de pesquisa universitários, cuja participação foi nula em sua elaboração e implementação. Hoje se projetam grandes obras públicas (como a ampliação do Porto de Salvador, a Via Expressa, o Polo Naval, a Ponte Salvador-Itaparica etc.) que forçosamente produzirão impactos ambientais e sociais. Ponderou-se que esses impactos podem ser minorados se os estudos competentes forem seguidos de debate crítico em um foro metropolitano e de consultas sistemáticas à sociedade. O Governador do Estado concordou com essas ponderações, mas nenhuma medida concreta foi tomada para fazer valer as propostas que lhe foram levadas na oportunidade.

Em suma, não houve qualquer avanço. Não há um Plano Diretor Metropolitano para essa região, que engloba a maior e mais importante área da Bahia de Todos os Santos (BTS), que continua a ser uma Área de Proteção Ambiental (APA) sem plano de manejo. Seu zoneamento econômico e ecológico até agora não se realizou. Tampouco existe um Conselho Intermunicipal que se empenhe no ajuste de políticas públicas nesse espaço, embora seja gritante sua necessidade. $\mathrm{O}$ anunciado Plano Diretor da BTS tampouco se efetivou. Mas pululam intervenções pontuais e grandes projetos estão sendo lançados.

Na urbe que nucleia a RMS (uma cidade com cerca de dois milhões e seiscentos mil habitantes, enquanto os outros municípios

à sociedade civil organizada, particularmente aos movimentos pela moradia e inclusão social, que, na luta pelos seus direitos, consolidaram a avançada legislação urbana representada pelo Estatuto da Cidade. não passam, em média, dos quatrocentos mil), o planejamento urbano há muito que está em crise: a rigor, deixou de existir nas últimas décadas. Evidência dessa crise é a trajetória truncada da implantação do Plano Diretor do Desenvolvimento Urbano (PDDU) de Salvador, cuja aprovação à sorrelfa e cujas precipitadas reformas foram questionadas judicialmente pelo Ministério Público e por importantes setores da sociedade civil organizada. Uma Lei de Ordenamento do Uso e Ocupação do Solo Urbano (LOUOS), que deveria regulamentá-lo, incluiu emendas ao PDDU antes barradas pela Justiça por não se conformarem aos trâmites legais - e foi votada às escuras. Em face de liminar que se lhe opôs, nova versão foi encaminhada à Câmara dos Vereadores sem que se desse tempo para exame responsável pelos edis. Também esta nova LOUOS teve questionada sua aprovação, feita sem as devidas consultas públicas e sem a apreciação pelo Conselho da Cidade, como previsto em lei. Deu-se um novo impasse, com o pronto questionamento das ilegalidades acusadas pelo Ministério Público. O resultado é o embaraço legal que complica uma situação de pura desordem urbana hoje verificada na capital da Bahia.

Entre outras coisas, é digno de nota o fato de que o PDDU de Salvador, na versão ainda em vigor, não faz referência à RMS e minimiza a importância da Bahia de Todos os Santos, embora vise a uma urbe conhecida popularmente como Cidade da Bahia.

Em suma, Salvador, a mais antiga e uma das mais importantes metrópoles brasileiras, não é tratada como metrópole. Sua gestão lhe ignora o entorno, o nicho do qual ela compõe um poderoso núcleo.

Na verdade, constata-se um colapso do planejamento urbano e regional no Estado da Bahia. Vale repetir: planejamento de verdade tem de ser sistêmico e participativo. O quesito "participação democrática" é de vital importância. Um instrumento fundamental que pode garantir isso são os conselhos comunitários. Mas é preciso que eles sejam constituídos 
como se deve e sempre respeitados.

Isso não acontece na Bahia. Basta que se pense na reforma do Conselho Estadual de Preservação Ambiental (CEPRAM), que lhe alterou a composição em prejuízo da participação da sociedade civil e lhe tirou, na prática, o poder deliberativo, limitando de forma severa seu funcionamento. A instituição de um processo de autolicenciamento ambiental coroou o desarranjo.

A Lei Estadual (LE) 12.377/2011 provocou alterações significativas tanto na $\mathrm{L}$. E. de $\mathrm{n}^{\circ} 10.431 / 2006$, que dispõe sobre a Política Estadual de Meio Ambiente e de Proteção à Biodiversidade, como na Lei 11.612/2009, relativa à Política Estadual de Recursos Hídricos. Alterou também a Lei 11.051/2008 que reestrutura o Grupo Operacional de Fiscalização e Regulação. O Ministério Público Estadual (MPE-BA) reagiu a essas alterações abusivas, encaminhando exposição de motivos à Associação Brasileira dos Membros do Ministério Público de Meio Ambiente (ABRAMPA), que ingressou com uma representação junto à Procuradoria Geral da República (PGR), pedindo a propositura de Ação Direta de Inconstitucionalidade (ADIN) perante o Supremo Tribunal Federal, com vistas a sanar inconstitucionalidades e ilegalidades da L. E. $\mathrm{n}^{\circ}$ 12.377/2011. Um dos principais pontos questionados pelos - membros do MPE foi justamente a diminuição స్ da participação popular nos processos de li荌 cenciamento ambiental. produza para si mesmo, por meio eletrônico, uma licença ambiental - e, assim, fique imediatamente autorizado a deflagrar sua atividade, sem passagem por outro crivo. Os efeitos desse laissez-faire só podem ser negativos, mesmo se o empreendimento for de baixo impacto. Nos casos de médio (ou alto) potencial poluidor, será certamente grave a consequência de semelhante arbítrio. Segundo assinalou com absoluta pertinência o promotor de Justiça Marcelo Guedes, coordenador do Centro de Apoio Operacional às Promotorias de Justiça do Meio Ambiente (CEAMA), a LAC retira o poder discricionário da Administração Pública de fazer análise prévia dos impactos que o empreendimento pode gerar no meio ambiente, além de ferir o princípio da precaução, que implica uma ação antecipatória à ocorrência do dano ambiental. Observaram ainda ilustres membros do Ministério Público que, desse modo, a lei em tela subtraiu do ordenamento jurídico ambiental do Estado da Bahia a competência licenciatória do órgão colegiado, ao tempo em que retirou a previsão normativa das consultas públicas anteriores à audiência pública, afastando a sociedade da participação nas decisões de relevante interesse no plano ambiental. ${ }^{9}$ Não resta dúvida de que isso aumentou a vulnerabilidade de importantes ecossistemas do território baiano.

Em suma, temos agora um CEPRAM mutilado. Mas ele não é o único Conselho importante nesta situação. O Conselho Estadual de Justiça e Direitos Humanos praticamente não se reúne. A Associação Baiana de Imprensa retirou-se dele por considerá-lo ineficiente e pouco democrático.

Em Salvador, o ex-prefeito Carneiro ignorou as exigências da lei e as reclamações da sociedade civil, protelando abusivamente a implantação do Conselho Municipal da Cida-

${ }^{9}$ Além disso a malfadada lei instituiu que a perfuração de poços tubulares poderá ser dispensada de outorga de direito de uso de recursos hídricos ou de manifestação prévia, contrariando o que dispõe a Política Nacional de Recursos Hídricos (Lei $\left.n^{\circ} 9.433 / 97\right)$, que prescreve a obrigatoriedade de outorga para uso de águas subterrâneas através dos poços tubulares. 
de; quando, por fim, o instalou, nos últimos dias de sua segunda gestão, tirou-lhe o poder deliberativo preconizado pela legislação federal, além de alterar-lhe a composição. Seu sucessor, até o momento, não se definiu no tocante a isso; apenas instituiu, por decreto, um Conselho de Salvador com caráter meramente consultivo, ligado a seu gabinete.

Essa castração de conselhos ocorre em outras regiões do Brasil. Muitos dos nossos governantes ainda veem a participação democrática na gestão como um óbice, um embaraço que se esforçam por contornar.

É comum, também, que as consultas públicas sobre temas de vital importância para o povo sejam dispensadas, em detrimento do que reza a lei. Quando são realizadas, perfazem-se de forma inconsequente, perfunctória, com uma espécie de rito bisonho em que autoridades proferem longas exposições, cansativas, mas inócuas, com o único propósito de gastar o tempo e, assim, restringir a fala dos representantes da sociedade civil. Por vezes, escolhem-se datas e horários em que se torna difícil o comparecimento do público interessado. Em geral, os dados técnicos são apresentados sem que se tenha o cuidado de traduzi-los em linguagem compreensível para todos, ou são expostos de maneira tão esquemática, imprecisa e críptica, que mesmo especialistas, sem o tempo necessário para um exame adequado, têm dificuldade de entender e discutir as propostas. Os documentos pertinentes raras vezes são disponibilizados. Sucede ainda que as colocações feitas por membros de movimentos sociais e de outros setores da sociedade civil sejam tranquilamente ignoradas. Nesses casos, a audiência se transforma em jogo de cena, destinado a simular o cumprimento de uma obrigação legal. Concluído o espetáculo, o projeto segue seu curso como havia sido predeterminado, esquecidas as ponderações, os reparos e as objeções dos "consultados". Porém o mais comum é que a informação sobre planos e projetos capazes de afetar a vida da população seja "economizada”, mantida longe do conhecimento geral - ou, no máximo, exposta em linguagem publicitária, em código de marketing. O mais grave é que os necessários estudos de impacto são geralmente eludidos e nunca (ou quase nunca) apresentados. Alternativas para um procedimento julgado necessário não são consideradas à luz desses estudos.

Essa situação não constitui uma novidade. Já em 2004, a propósito do desenvolvimento e planejamento urbano, o relator especial das Nações Unidas para a Moradia Adequada, Miloon Khotari, em sua visita ao Brasil, informava:

[...] testemunhei uma contradição com relação aos processos participativos. Ainda que a democracia e a sociedade civil sejam fortes e, ainda mais, que o governo federal em particular tente assegurar a participação no processo de decisão aliado à realização de conferêcias nacionais, existe uma lacuna de participação real no planejamento e desenvolvimento de planos e alocações de recursos a nível local. O Estatuto da Cidade se constitui em um instrumento para a elaboração participativa no desenvolvimento de planos e alocação de recursos e prevê mecanismos inovadores relativos a: zonas especiais de interesse social, estudos de impacto de vizinhança, segurança da posse e regularização fundiária. No entanto, de acordo com depoimentos dados sobre o desenvolvimento do Plano Diretor de cidades como Fortaleza e Salvador, onde importantes recursos são gerados a partir do turismo, o acesso a tal participação e desenvolvimento do planejamento urbano tem sido negado a movimentos da sociedade civil, apesar de, no caso de Salvador, existir uma ordem judicial (Khotari, 2004, p. 6).

A democracia representativa não é suficiente para assegurar o Estado de direito. Como demonstrado por Holston (2008) os processos e práticas que definem a cidadania são "inerentemente disjuntivos e não cumulativos. Não são lineares nem igualmente distribuídos entre cidadãos, antes envolvem uma mistura de elementos regressivos e progressivos" (Holston, 2008, p. 311 tradução nossa). Torna-se necessário, portanto, que diversos grupos de interesse tenham garantida a possibilidade de participar do debate público, da contínua negociação de direitos.

Não se pode desprezar a dimensão material da política. Coisas como acesso a água, 
infraestrutura sanitária, saúde, segurança e integridade do corpo não podem ser negligenciados na consideração da cidadania. Não importam menos do que a prerrogativa de votar (Holston, 2008). Ponderando esses fatos, conclui-se que a vulnerabilidade política desdobra-se em outras vulnerabilidades.

As características brutais dos processos de violência fria costumam ser mascaradas por discursos ideológicos celebrativos da "modernização" e do "desenvolvimento", utilizados para produzir ou induzir um consenso, ou aparentá-lo, forjando, assim, uma identificação entre a população e um Estado extremamente "desigualitário" na distribuição de recursos e direitos. O efeito desses discursos torna-se visível no diálogo com os grupos afetados por semelhantes processos. Eles frequentemente não sabem como defender-se, nem contra quem. São vítimas dos danos colaterais de um desenvolvimento que, de saída, os exclui.

Recebido para publicação em 09 de agosto de 2014 Aceito em 22 de julho de 2015

\section{REFERÊNCIAS}

BANDEIRA DE MELlO, C. A. Curso de Direito Administrativo. 18. ed. São Paulo: Malheiros, 2005.

BRASILINO, L. Quando o réu vira vítima. Entrevista com Fausto de Sanctis. Le Monde Diplomatique, São Paulo, Instituto Pólis, no. 50, p. 4, set. 2011.

CASSIDY, J. How markets fail: the logic of economic calamities. New York: Farrar, Straus and Giroux, 2010.

FREITAS, J. De. Autores de desgraças. Jornal a Tarde, Salvador, 8 de janeiro de 2013, p. B7.

HOLSTON, J. Insurgent Citizenship: Disjunctions of Democracy and Modernity in Brazil. Princeton, NJ: Princeton University Press, 2008.

KHOTARI, M. Observações preliminares do relator especial das Nações Unidas para a moradia adequada, Sr. Miloon Khotari, sobre sua missão ao Brasil (30 mai.11 jun. 2004) in Coletiva de Imprensa. Salvador, 11 jun. 2004, 10p. Disponível em: http://www.polis.org.br/ uploads/911/911.pdf . Acesso em: 25 jun. 2013.

KRUGMAN, P. Corporate cash con. In: The New York Times, New York, 3 jul. 2011.

KYMLICKA, W. Multicultural Citizenship. In: SHAFIR, G. (org.) The Citizenship Debates: A reader. Minneapolis: University of Minnesota Press, 1998. p. 167-188.

MARSHALL, T.H. Citizenship and Social Class. In SHAFIR, G. (org.) The Citizenship Debates: A reader. Minneapolis: University of Minnesota Press, 1998. p. 93-112.

SASSEN, S. The Repositioning of Citizenship: Emergent Subjects and Spaces for Politics. Berkeley Journal of Sociology, Berkeley, n. 46, 2003. p. 4-25.

UNAMUNO, M. de. Del sentimento trágico de la bida en los hombres y en los pueblos. Madrid: Renacimiento, 1930 1983 . La agonia del Cristianismo. Madrid: Editora Akal,

YOUNG, I.M. Polity and group difference. In SHAFIR, G. (org.) The Citizenship Debates: A reader. Minneapolis: University of Minnesota Press, 1998. p. 263-290. 


\section{CONSIDERATIONS ABOUT COLD VIOLENCE}

\author{
Ordep Serra \\ Lorena Volpini
}

The authors discuss the concept of vulnerability and apply it to the horizon of politics with the goal of talking about politics vulnerability and relate it to was they call "cold violence", that is, the one where agents have institutional protection that reduces or cancels their liability, due to the postponement of the effects of the predatory action and to how impersonal their relationship with the victims is, but also due to pressures on governments and control agencies. They discuss the issue of citizenship in highly unequal scenarios and examine the factors that make populations more or less politically vulnerable to socio-environmental damage. Among these factors they consider the manipulation of urban and regional planning with its limiting collaborative character and the interferences of private interests on public affairs during this policy-making. They also examine the recurrent confusion between 'government interest' and 'public interests'.

Keywords: Cold violence. Vulnerability. Planning. Citizenship. Inequality.

\section{CONSIDÉRATIONS SUR LA VIOLENCE FROIDE}

\author{
Ordep Serra \\ Lorena Volpini
}

Les auteurs discutent de la notion de vulnérabilité et l'appliquent au domaine de la politique. Ils proposent d'analyser la vulnérabilité politique et d'établir le lien avec ce qu'ils appellent "la violence froide”. En d'autres termes, celle pour laquelle les agents de cette violence arrivent à se blinder institutionnellement afin de réduire ou d'annuler les responsabilités en raison du retard de ses effets prédateurs et de l'impersonnalité de sa relation avec les victimes, mais aussi par la pression exercée sur les gouvernements et les organismes de réglementation. C'est bien à propos que la question de la citoyenneté est remise en cause dans le cadre de grandes inégalités et que les facteurs qui rendent les populations plus ou moins vulnérables politiquement à des dommages environnementaux sont pris en considération. Parmi ces facteurs, la manipulation de la planification urbaine et régionale, avec ses limitations d'un point de vue participatif et l'interférence d'intérêts privés dans l'administration publique, au niveau de cette politique de décision (policy-making) . Par ailleurs, ils examinent aussi la confusion délibérée et constante entre "les intérêts de gouvernement" et "les intérêts publics".

Mots-CLÉs: Violence froide. Vulnérabilité. Planification. Citoyenneté. Inégalité.

Ordep Serra - Doutor em Antropologia. Professor participante do Programa de Pós-Graduação em
Antropologia da Universidade Federal da Bahia - UFBA. Membro da Associação Brasileira de Antropologia,
da Sociedade Brasileira de Estudos Clássicos e da SBPC. Coordenador do Movimento Vozes de Salvador
e membro do Fórum "A Cidade Também é Nossa". Produção principal em Antropologia da Religião,
Antropologia das Sociedades Clássicas, Teoria Antropológica. Publicações recentes: Os olhos negros do
Brasil, a ser publicado pela Editora da UFBA (no prelo); Breve reflexão sobre os hinos órficos. Revista da
Academia de Letras da Bahia, v. 52, p. 73-92, 2014; Comentário ao artigo Pink, Green and Black. Debates
do NER, v. 00, p. 227, 2012; A tenacidade do racismo. Tempo e Presença Digital (Online), v. 00, p. 127-
149, 2011.
Lorena Volpini - Doutoranda em Antropologia nesta mesma instituição. Atualmente bolsista FAPESB
e membro do grupo de Pesquisa Panoramas Urbanos (UFBA). Seus interesses de pesquisa envolvem
a antropologia urbana, em particular os processos de engajamento coletivo em disputas sobre espaço
urbano e reivindicações de participação na cidade de Salvador. Publicações recentes:A diferença é cidadã:
Uma reflexão sobre cidadania a partir das demandas por direitos de povos e comunidades tradicionais
do Brasil. In: Júlio Cesar de Sá Rocha; Ordep Serra. (Org.). Direito ambiental conflitos socioambientais e
comunidades tradicionais. 1ed.Salvador: Edufba,p. 63-80, 2015; Vizinhança e lealdade, fofoca e prestígio:
conhecendo regras e valores em um bairro popular da velha Salvador. In: Urpi Montoya Uriarte; Milton
Júlio de Carvalho Filho. (Org.). Panoramas urbanos: usar, viver e construir Salvador. 1ed.Salvador. p.
177-201, 2014. 
